\title{
Protein ingestion preserves proteasome activity during intense aseptic inflammation and facilitates skeletal muscle recovery in humans
}

\author{
Dimitrios Draganidis ${ }^{1}$, Niki Chondrogianni ${ }^{2}$, Athanasios Chatzinikolaou ${ }^{3}$, Gerasimos Terzis ${ }^{4}$, \\ Leonidas G. Karagounis ${ }^{1,5}$, Apostolos Sovatzidis ${ }^{6}$, Alexandra Avloniti ${ }^{3}$, Maria Lefaki ${ }^{2}$, Maria Protopapa ${ }^{3}$, \\ Chariklia K. Deli ${ }^{1}$, Konstantinos Papanikolaou ${ }^{1}$, Athanasios Z. Jamurtas ${ }^{1,7}$ and Ioannis G. Fatouros ${ }^{1 *}$ \\ ${ }^{1}$ School of Physical Education and Sport Sciences, University of Thessaly, Karies, Trikala 42100, Greece \\ ${ }^{2}$ Medicinal Chemistry and Biotechnology, National Helenic Research Foundation, Institute of Biology, 48 Vas. Constantinou \\ Ave., 11635 Athens, Greece \\ ${ }^{3}$ School of Physical Education and Sport Sciences, Democritus University of Thrace, 69100 Komotini, Greece \\ ${ }^{4}$ Athletics Laboratory, School of Physical Education and Sport Sciences, National and Kapodistrian University of Athens, \\ 41 Ethnikis Antistaseos Ave., 17237 Athens, Greece \\ ${ }^{5}$ Nestlé Research Center, Nestec Ltd, Lausanne 1000, Switzerland \\ ${ }^{6}$ General Hospital of Thessaloniki 'Agios Dimitrios', Surgery Department, Thessaloniki 546 34, Greece \\ ${ }^{7}$ Center for Research and Technology-Thessaly, Institute of Human Performance and Rehabilitation, Trikala 42100, Greece
}

(Submitted 17 January 2017 - Final revision received 9 May 2017 - Accepted 5 June 2017)

\section{Abstract}

The ubiquitin-proteasome system (UPS) is the main cellular proteolytic system responsible for the degradation of normal and abnormal (e.g. oxidised) proteins. Under catabolic conditions characterised by chronic inflammation, the UPS is activated resulting in proteolysis, muscle wasting and impaired muscle function. Milk proteins provide sulphur-containing amino acid and have been proposed to affect muscle inflammation. However, the response of the UPS to aseptic inflammation and protein supplementation is largely unknown. The aim of this study was to investigate how milk protein supplementation affects UPS activity and skeletal muscle function under conditions of aseptic injury induced by intense, eccentric exercise. In a double-blind, cross-over, repeated measures design, eleven men received either placebo (PLA) or milk protein concentrate (PRO, $4 \times 20 \mathrm{~g}$ on exercise day and $20 \mathrm{~g} / \mathrm{d}$ for the following 8 days), following an acute bout of eccentric exercise (twenty sets of fifteen eccentric contractions at $30 \%$ s) on an isokinetic dynamometer. In each trial, muscle biopsies were obtained from the vastus lateralis muscle at baseline, as well as at 2 and $8 \mathrm{~d}$ post exercise, whereas blood samples were collected before exercise and at $6 \mathrm{~h}, 1 \mathrm{~d}$, $2 \mathrm{~d}$ and $8 \mathrm{~d}$ post exercise. Muscle strength and soreness were assessed before exercise, $6 \mathrm{~h}$ post exercise and then daily for 8 consecutive days. PRO preserved chymotrypsin-like activity and attenuated the decrease of strength, facilitating its recovery. PRO also prevented the increase of $\mathrm{NF}-\kappa \mathrm{B}$ phosphorylation and HSP70 expression throughout recovery. We conclude that milk PRO supplementation following exercise-induced muscle trauma preserves proteasome activity and attenuates strength decline during the pro-inflammatory phase.

Key words: Skeletal muscle damage: Protein supplementation: Muscle proteasome: Muscle strength performance: Aseptic inflammation

Strenuous exercise causes skeletal muscle microtrauma, which is characterised by ultrastructural damage of sarcomeres and cell membranes and results in a loss of force-generating capacity and muscle soreness ${ }^{(1)}$. This exercise-induced muscle damage (EIMD) activates an inflammatory response cascade leading to the sequential infiltration of neutrophils and macrophages into the injured muscle tissue, the production of pro-inflammatory cytokines and reactive oxygen species (ROS) at the injury site and elsewhere, as well as a systemic release of leucocytes and cytokines and oxidative stress ${ }^{(1,2)}$. Muscle damage and inflammation also characterise a number of catabolic diseases such as muscular dystrophies, cancer cachexia and sepsis, although with diverse mechanisms (e.g. different profile of released cytokines) ${ }^{(2)}$. Therefore, eccentric exercise appears to be a valid model to study the cellular and molecular pathways regulating the inflammatory process associated with physical trauma.

During the inflammatory phase, a rapid invasion of ROSgenerating immune cells (i.e. neutrophils and macrophages) is crucial for the efficient clearance of cellular debris, as well as

Abbreviations: CK, creatine kinase activity; CT-L, chymotrypsin-like; DOMS, delayed onset of muscle soreness; ES, effect size; PC, protein carbonyls; PLA, placebo; ROS, reactive oxygen species; UPS, ubiquitin-proteasome system.

* Corresponding author: I. G. Fatouros, fax +30 2431047042, email ifatouros@pe.uth.gr 
the subsequent repair and regeneration of muscle fibres. However, ROS produced during this phase by NADPH oxidase (respiratory burst) may also lead to marked perturbations of muscle redox status ${ }^{(1,3,4)}$. Furthermore, damaged myofibres and cytokines released from phagocytes activate ROS-generating enzymes such as xanthine oxidase, cyclo-oxygenase- 2 and NADPH oxidase ${ }^{(5)}$. ROS may cause secondary muscle damage of adjacent intact muscle fibres ${ }^{(1)}$, thereby exacerbating the loss of muscle's force-generating capacity ${ }^{(4)}$. It appears that these perturbations of redox status are involved in the regulation of transcriptional pathways such as those of $\mathrm{NF}-\kappa \mathrm{B}$, mitogenactivated protein kinases and protein kinase B (Akt)/mammalian target of rapamycin ${ }^{(4,6-8)}$. These cascades mediate the activation and recruitment of immune cells, adhesion molecules, satellite cells and synthesis of antioxidant enzymes ${ }^{(4,6-8)}$.

Increasing evidence suggests that elevated ROS production may down-regulate anabolic signalling and protein synthesis ${ }^{(9)}$ and promote oxidative protein modifications and proteolysis via the ubiquitin-proteasome system (UPS) - the main proteolytic system in skeletal muscle ${ }^{(9-12)}$. The $20 \mathrm{~S}$ proteasome is the ATPindependent proteolytic core, composed by $7 \alpha$-and $7 \beta$-subunits, three of which $\left(\beta_{1}, \beta_{2}\right.$ and $\left.\beta_{5}\right)$ are responsible for the specific proteolytic activities of the complex ${ }^{(12-14)}$. Furthermore, the immunoproteasome is also active in muscle under pro-inflammatory conditions. UPS activation in muscle, under proinflammatory conditions, is mediated by cytokines (i.e. TNFa and IL-6) and NF- $\kappa$ B signalling ${ }^{(15,16)}$. However, following EIMD, both proteasome- and immunoproteasome-mediated proteolysis promote degradation of damaged and/or unfolding proteins and facilitate myogenesis and recovery of muscle's functional capacity $^{(17,18)}$. Indeed, marked elevation in mRNA and protein expression level of specific E3 ubiquitin ligases persists up to $48 \mathrm{~h}$ following a single bout of eccentric exercise ${ }^{(19)}$.

Protein supplementation has been postulated to affect skeletal muscle's remodelling process, by regulating the inflammatory response ${ }^{(20)}$. Whey protein supplementation during recovery from eccentric exercise has been shown to prevent strength decline $^{(21-22)}$ and to accelerate satellite cell proliferation ${ }^{(23)}$. Moreover, branched-chain amino acids (BCAA) may also promote the attenuation of EIMD $^{(24)}$ and the delayed onset of muscle soreness (DOMS) following eccentric exercise ${ }^{(25)}$. However, protein is also a rich source of sulphur-containing amino acids that act as precursors for GSH synthesis, thereby protecting cells from redox status disturbances ${ }^{(26)}$. Although protein supplementation has been extensively examined in terms of stimulating muscle protein synthesis (MPS) following exercise, its ability to regulate both the inflammatory response and UPS following aseptic muscle injury remains unclear. Thus, we investigated the effects of milk protein concentrate supplementation on muscle damage, inflammatory responses, proteasome activity and muscle strength following muscle-damaging eccentric exercise.

\section{Methods}

\section{Participants}

All participants ( $n$ 11) were informed of the purpose of the study, the experimental procedures involved and all the risks, discomforts and benefits involved, before obtaining written consent. The study was approved by the Institutional Review Board of the University of Thessaly and procedures were in accordance with the 1975 Declaration of Helsinki, as revised in 2000. Participant's characteristics are shown in Table 1. Participants were recreationally active $\left(\mathrm{VO}_{2 \max }>45 \mathrm{ml} / \mathrm{kg}\right.$ per min) and had been engaged in systematic resistance exercise training of $\geq 3$ times/week for the past 12 months. For inclusion in the study, the criteria for participants were as follows: (1) non-smokers; (2) abstained from any vigorous physical activity during the experimental period; (3) had no consumption of alcohol, caffeine, any type of nutritional supplements and medication before (at least 6 months) and throughout the experimental period; (4) had no allergies or intolerance to milk protein; and (5) had no recent history of muscle lesions, lower limb trauma and metabolic diseases.

\section{Experimental design}

A two-trial, cross-over, double-blind, repeated measures design was used in this investigation. Before each trial, participants' body weight and height, RMR and body composition (dualenergy X-ray absorptiometry scan) were measured and they were then provided with accelerometers to measure their habitual physical activity and diet recalls in order to record their dietary intake, over a 7-d period. Thereafter, diet recalls were analysed and participants entered a 3 -week adaptive period to ensure that all of them received a standard protein intake of $1 \mathrm{~g}$ protein/kg per $\mathrm{d}$, which was considered to be the mean and population-safe protein intake ${ }^{(27,28)}$.

Participants were randomly assigned to consume either milk protein concentrate (PRO) or placebo (PLA), immediately after an acute bout of eccentric exercise on an isokinetic dynamometer and daily for 8 consecutive days post exercise (Fig. 1). A 6-week washout period was adapted between trials. Before each trial, muscle force-generating capacity was tested following familiarisation with the equipment while $\mathrm{VO}_{2 \max }$ was measured during a graded exercise test to exhaustion using an automated online gas exchange analyser as previously described ${ }^{(29)}$. Participants were asked to refrain from resistance exercise or any other strenuous physical activity for at least 2 weeks before each trial and throughout the experimental period. On each exercise day of each trial, participants arrived at the laboratory after an overnight fast, and baseline blood samples and muscle biopsies were collected. Subsequently, they performed an acute bout of unilateral eccentric contractions on an isokinetic dynamometer. Muscle biopsies and blood samples were also collected at 2 and $8 \mathrm{~d}$ after exercise, whereas muscle strength was evaluated at $6 \mathrm{~h}$ post exercise and daily for 8 consecutive days. All measurements were performed at the same time of day, in both trials, to prevent the effect of circadian variations.

\section{Exercise protocol}

The exercise protocol applied in the present study has been described to effectively induce myofibrillar disruption, as indicated by electron microscopy and immunohistochemistry ${ }^{(30)}$, and has been efficiently used in a previous study of our group to 


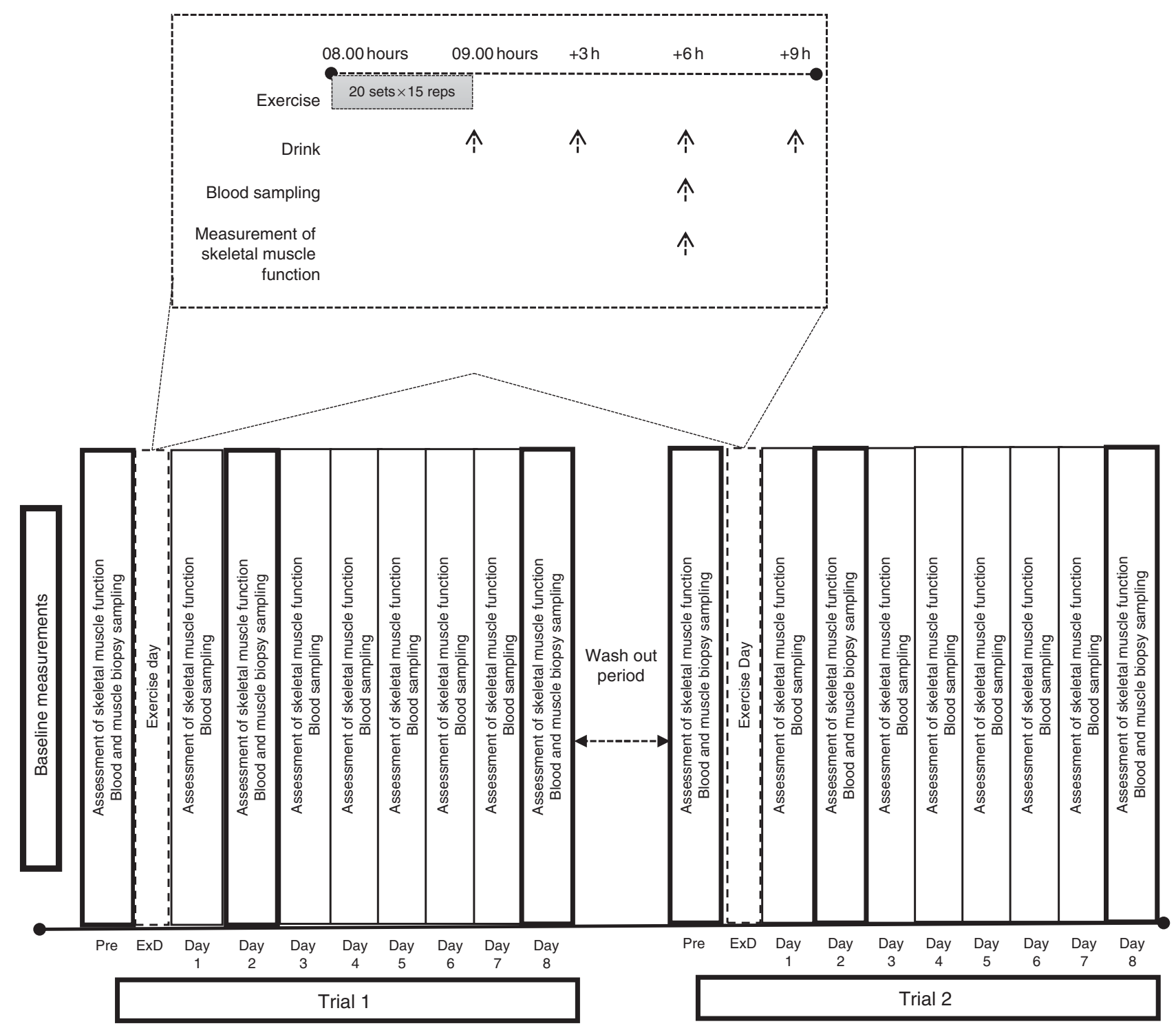

Fig. 1. Experimental design. ExD, exercise day.

induce aseptic inflammation ${ }^{(8)}$. In brief, participants performed 300 eccentric unilateral contractions (twenty sets, fifteen repetitions/set, 30-s rest between sets) of knee extensors on an Isoforce isokinetic dynamometer (TUR Gmbh) at a speed of $30 \%$ s.

\section{Supplementation}

On exercise day, participants consumed a protein supplement consisting of $80 \%$ protein ( $80 \%$ casein and $20 \%$ whey), $1.5 \%$ fat and $5 \%$ carbohydrates or a matching PLA (containing no protein) as repeated 'pulsed' drinks: immediately post exercise and then one every $3 \mathrm{~h}$ on three occasions $(+3,+6,+9 \mathrm{~h})$. According to previous reports ${ }^{(31,32)}$, distributing $80 \mathrm{~g}$ of protein in $4 \times 20 \mathrm{~g}$ doses every $3 \mathrm{~h}$ is superior to either pulse ( $8 \times 10 \mathrm{~g}$ every $1.5 \mathrm{~h}$ ) or bolus $(2 \times 40 \mathrm{~g}$ every $6 \mathrm{~h})$ feeding in stimulating MPS and maximising whole-body protein balance over a 12 -h post-exercise period. On each day of the remaining days, participants consumed a single drink (protein or PLA) with breakfast. A single dose of $20 \mathrm{~g}$ of protein supplemented on non-exercise days is considered the minimum amount of protein required in order to increase protein intake on non-training days ${ }^{(33,34)}$. Each PLA supplement contained $20 \mathrm{~g}$ of maltodextrin to keep the two supplements isoenergetic. All drinks were prepared in $250 \mathrm{ml}$ of water and flavoured with bannana, to make the contents indistinguishable and non-transparent.

\section{Muscle performance}

To assess muscle performance, maximal knee extensor eccentric peak torque was measured on the same isokinetic dynamometer at $60 \%$ as described ${ }^{(30)}$. The evaluation was preceded by a familiarisation period (CV for repeated measures was $4 \cdot 1 \%$ ). Participants rated their DOMS on a visual analogue scale (1-10) during palpation of the muscle belly and the distal region of relaxed vastus medialis, vastus lateralis and rectus femoris, following three repetitions of a full squat ${ }^{(35)}$. 


\section{Diet records}

In the beginning of the study, participants were taught (by a trained dietitian) how to estimate food servings and sizes and how to record their regular dietary intake. Then, participants completed 7-d diet recalls to evaluate their protein and energy intake. On the basis of diet analysis, participants were provided with a dietary plan providing 1.0 (SD 0.02$) \mathrm{g}$ protein $/ \mathrm{kg} /$ day over a 3 -week period (adaptive period). During the first trial (8-d testing period), as well as during the washout period and the second trial (8-d testing period), participants completed again 7-d diet recalls to record their daily intake to verify that they followed the same diet practice as they did in the preliminary adaptive period. Analysis of diet recalls collected throughout the study indicated a similar diet composition (total energy: 2581.7 (SD 105.4)\%, carbohydrate intake: $56 \cdot 3$ (SD $3 \cdot 1) \%$, fat intake: $28 \cdot 1$ (SD 3.1) \%, protein intake: $15 \cdot 6$ (SD 1.5)\%) of participants during all phases of the study (adaptive period, trial 1, washout period, trial 2). Science Fit Diet 200 A (Science Technologies) was used for the analysis of diet records.

\section{Blood sampling and assays}

Resting blood samples were collected at 07.00 hours on the exercise day, after an overnight fast. All samples were collected via a 20-gauge disposable needle equipped with a Vacutainer tube holder (Becton Dickinson) from an antecubital arm vein, while subjects were in a seated position. For serum separation, blood samples were allowed to clot at room temperature first and then centrifuged $\left(1500 \mathbf{g}, 4^{\circ} \mathrm{C}, 15 \mathrm{~min}\right)$. The supernatant was dispensed in multiple aliquots (into Eppendorf tubes) that were stored at $-80^{\circ} \mathrm{C}$ for later analysis of creatine kinase activity (CK). A blood portion was collected into tubes containing EDTA and centrifuged $\left(1370 \mathrm{~g}, 4^{\circ} \mathrm{C}, 10 \mathrm{~min}\right)$. Plasma was collected into Eppendorf tubes and stored at $-80^{\circ} \mathrm{C}$, and it was used for the measurement of insulin and glucose. The remaining plasma erythrocytes were then lysed and the resultant lysate was collected as described ${ }^{(36)}$ and used for analysis of protein carbonyls $^{(37)}$. Another blood portion $(2 \mathrm{ml})$ was immediately collected in EDTA tubes and were used for the determination of leucocyte count using an automated haematology analyzer (BC-5500; Shenzhen Mindray). CK and glucose concentrations were measured using a Clinical Chemistry Analyser Z1145 (Zafiropoulos Diagnostica) using commercially available kits (Zafiropoulos). Insulin was measured with a commercially available insulin (Human) ELISA kit (Abnova ${ }^{\mathrm{R}}$ corporation). Protein carbonyls (PC) were assayed spectrophotometrically (Hitachi UV/ VIS; Hitachi Instruments Inc.) at $375 \mathrm{~nm}$, as described ${ }^{(35)}$. Plasma and serum samples were stored in multiple aliquots at $-80^{\circ} \mathrm{C}$ and thawed only once before analysis. All assays were performed in duplicate. Inter- and intra-assay coefficients of all assays ranged from 1.8 to $8.2 \%$ and from 2.9 to $8.6 \%$, respectively.

\section{Muscle biopsy sampling}

Muscle samples were obtained using the standard Bergström needles, with suction, from the middle portion of vastus lateralis of the exercising leg under local anaesthesia (xylocaine $1 \%)^{(38)}$. The pre-exercise sample was obtained $25 \mathrm{~cm}$ from mid-patella, $30 \mathrm{~min}$ before exercise. Subsequent biopsies (at 2 and $8 \mathrm{~d}$ post exercise) were obtained from the same muscle, $5 \mathrm{~cm}$ distal to each previous biopsy site. A different limb (randomly selected) was used for eccentric exercise and biopsy sampling in each trial. Adipose tissue and blood were carefully removed from muscle samples that were rapidly frozen in $\mathrm{N}_{2}$ and stored at $-80^{\circ} \mathrm{C}$ for further analysis of protein phosphorylation, proteasome activity and expression of its catalytic subunits.

\section{Proteasome peptidase assay}

This method allows the direct quantification of proteasome activities and is performed as previously described ${ }^{(39,40)}$. In brief, tissue samples were homogenised in proteasome activity lysis buffer ( $1 \mathrm{~m}$ Tris- $\mathrm{HCl}, \mathrm{pH} 7 \cdot 6,100 \mathrm{~mm} \mathrm{ATP,} 3 \mathrm{~m} \mathrm{KCl,} 0 \cdot 1 \mathrm{~m}$ EDTA, $1 \mathrm{~m}$ dithiothreitol, $0 \cdot 2 \% \mathrm{NP}-40,10 \%$ glycerol, $10 \mu \mathrm{g} / \mathrm{ml}$ aprotinin and $10 \mathrm{~mm}$ phenylmethylsulfonyl fluoride (PMSF)). Chymotrypsin-like (CT-L), caspase-like (C-L) and trypsin-like (T-L) activities were assayed with hydrolysis of the fluorogenic peptide LLVY-AMC, LLE-AMC and LSTR-AMC, respectively (Enzo Life Sciences), for $30 \mathrm{~min}$ at $37^{\circ} \mathrm{C}$. Specific activity was determined in the presence of $20 \mu \mathrm{m}$ MG132-specific proteasome inhibitor. Fluorescence was measured in the Safire ${ }^{2}$ Multidetection Microplate Reader (Tecana).

\section{Immunoblot analysis}

Immunoblot analysis was used to detect protein expression levels of proteasome $(\beta 5, \beta 2$ and $\beta 1)$ and immunoproteasome $(\beta 5 \mathrm{i}, \beta 2 \mathrm{i}$ and $\beta 1 \mathrm{i})$ subunits. A portion of the tissue samples that were homogenised during the proteasome peptidase assay was boiled in non-reducing Laemmli buffer (NRLB) for $10 \mathrm{~min}$, as previously described ${ }^{(39)}$. SDS-PAGE and immunoblotting were then contacted with specific antibodies against $20 \mathrm{~S}$, $19 \mathrm{~S}$, proteasome complexes and immunoproteasome. GAPDH was used as a loading control. Each immunoblot was repeated at least twice.

\section{Antibodies}

Polyclonal NF- $\kappa \mathrm{B}$ p $65^{\text {Ser536 }}$ was purchased from Cell Signaling Technology Inc. GAPDH was purchased from Santa Cruz Biotecnology Inc. Anti-rabbit (IgG, horseradish peroxidase linked) secondary antibody was also purchased from Signaling Technology Inc. Antibodies against $\beta 2, \beta 1, \beta 5, \beta 2 \mathrm{i}, \beta 1 \mathrm{i}$ and $\beta 5 \mathrm{i}$ proteasome subunits were purchased from Enzo Life Sciences and antibody against HSP70 was purchased from Santa Cruz Biotechnology.

\section{Measurement of intracellular-signalling-related proteins}

Changes in the phosphorylation of NF- $\kappa \mathrm{B}$ p $65^{\text {Ser536 }}$ and protein expression of HSP70 were analysed by immunoblotting. Briefly, muscle samples (approximately 40-50 mg) were homogenised in activity lysis buffer and then centrifuged at $13000 \mathrm{rpm}$ at $4^{\circ} \mathrm{C}$ 
for $10 \mathrm{~min}$ and the supernatant was collected. Total protein concentration was measured (Bradford Protein Assay; Bio-Rad) to prepare working samples of equal concentration in NRLB. Equal amounts of protein $(20 \mu \mathrm{g})$ were loaded onto $8 \%$ or gradient precast gels (Mini-PROTEAN TGX Gels; Bio-Rad) and separated by SDS-PAGE electrophoresis. Immediately after, proteins were transferred to nitrocellulose membrane, blocked with $5 \%$ non-fat milk/Tris-buffered saline for $1 \mathrm{~h}$ and incubated with primary antibody overnight at $4^{\circ} \mathrm{C}$. Membranes were washed with Tris-buffered saline-Tween (TBS-T) and incubated with secondary antibody for $1 \mathrm{~h}$ at room temperature. Subsequently, membranes were washed again with TBS-T, exposed, visualised by chemiluminescence and quantified by densitometry. Phosphorylation status of NF- $\kappa \mathrm{B}$ and HSP70 expression was then expressed relative to a corresponding GAPDH from the equivalent sample lysate.

\section{Statistics}

On the basis of a preliminary power analysis, a sample size of ten to twelve subjects was suggested in order to detect differences between repeated measurements with a power of $80 \%$ at a significance level of 5\% ( $\alpha$ error). Accordingly, fourteen healthy, trained male volunteers were recruited in the present study, but data from eleven volunteers have been analysed (for three participants, biopsy samples were not collected at all time points or the quantity of muscle tissue was not adequate for analysis).

All data are presented as means and standard deviations. A two-way (trial (PRO and PLA) $\times$ time (before exercise, and 2 and $8 \mathrm{~d}$ post exercise)) repeated measures ANOVA with planned contrasts on different time points was used to determine the effects of treatment and time on dependent variables. Bonferonni test was used for post hoc analysis, when a significant main effect was detected. Significance was set at $P<0.05$. Effect sizes (ES) were also calculated on results of CT-L proteasome activity. We also conducted bivariate Pearson's correlation analysis to estimate the relation of changes in skeletal muscle performance (isometric peak torque) and DOMS with proteasome function (activity and expression level of different $\beta$-subunits). Correlation coefficients of $r<0.2, \quad 0.2<r<0.7$ and $r>0.7$ were characterised as small, moderate and high, respectively. The level of statistical significance was set at $P<0.05$. All analyses were performed using the SPSS 20.0 software (IBM SPSS Statistics)

\section{Results}

\section{Participants' physical characteristics and dietary profile}

Participants' characteristics are presented in Table 1. The dietary profile was similar among trials, with the exception of protein intake (Table 2). Baseline values of muscle performance variables were indistinguishable between trials (Fig. 2), indicating that the 6 -week washout period was efficient in eliminating the systemic inflammatory responses induced by the first trial.
Table 1. Participants' characteristics in each trial* (Mean values and standard deviations)

\begin{tabular}{|c|c|c|c|c|}
\hline & \multicolumn{2}{|c|}{ Placebo trial } & \multicolumn{2}{|c|}{ Protein trial } \\
\hline & Mean & SD & Mean & SD \\
\hline Age (years) & 22 & 1.4 & 22 & 1.4 \\
\hline Body mass (kg) & $79 \cdot 4$ & $11 \cdot 1$ & 78.9 & $10 \cdot 3$ \\
\hline Height (m) & $1 \cdot 78$ & 0.06 & 1.78 & 0.06 \\
\hline BMI $\left(\mathrm{kg} / \mathrm{m}^{2}\right)$ & $25 \cdot 06$ & $2 \cdot 85$ & 24.92 & 2.63 \\
\hline Body fat (\%) & $15 \cdot 31$ & $1 \cdot 77$ & $15 \cdot 21$ & 1.67 \\
\hline $\mathrm{VO}_{2 \max }(\mathrm{ml} / \mathrm{kg}$ per min $)$ & $56 \cdot 47$ & $6 \cdot 82$ & $56 \cdot 1$ & $6 \cdot 86$ \\
\hline Resting metabolic rate $(\mathrm{kJ} / \mathrm{d})$ & $7930 \cdot 3$ & $635 \cdot 1$ & $8092 \cdot 2$ & $763 \cdot 2$ \\
\hline Resting metabolic rate $(\mathrm{kcal} / \mathrm{d})$ & $1895 \cdot 4$ & $151 \cdot 8$ & $1934 \cdot 1$ & 182.4 \\
\hline
\end{tabular}

* Participants demonstrated comparable anthropometric profile and physical conditioning status at baseline $(n 11)$. One-way (time) repeated measures ANOVA was used. $\mathrm{VO}_{2 \max }$, maximal $\mathrm{O}_{2}$ uptake.

Table 2. Daily total dietary energy intake and macronutrient consumption during the course of placebo (PLA) and protein (PRO) trials (protein supplement not included)

(Mean values and standard deviations)

\begin{tabular}{|c|c|c|c|c|}
\hline & \multicolumn{2}{|c|}{ PLA } & \multicolumn{2}{|l|}{ PRO } \\
\hline & Mean & SD & Mean & SD \\
\hline Daily energy intake (kJ) & $11588 \cdot 8$ & $557 \cdot 3$ & $11671 \cdot 3$ & 592.5 \\
\hline Daily energy intake (kcal) & 2769.8 & $133 \cdot 2$ & 2789.5 & $141 \cdot 6$ \\
\hline $\begin{array}{l}\text { Daily carbohydrate intake (\% of } \\
\text { total energy content) }\end{array}$ & $56 \cdot 2$ & $4 \cdot 2$ & $56 \cdot 4$ & 3.9 \\
\hline $\begin{array}{l}\text { Daily fat intake (\% of total energy } \\
\text { content) }\end{array}$ & $27 \cdot 3$ & 3.5 & $27 \cdot 5$ & $3 \cdot 8$ \\
\hline $\begin{array}{l}\text { Daily protein intake (\% of total } \\
\text { energy content) }\end{array}$ & $16 \cdot 5$ & $2 \cdot 4$ & $16 \cdot 1$ & $2 \cdot 2$ \\
\hline Protein intake on exercise day (g) & 1.02 & 0.2 & $2.05^{\star}$ & 0.5 \\
\hline $\begin{array}{l}\text { Protein intake during recovery days } \\
\quad(\mathrm{g} / \mathrm{kg} \text { per } \mathrm{d})\end{array}$ & 1.02 & $0 \cdot 2$ & $1 \cdot 29^{*}$ & 0.3 \\
\hline
\end{tabular}

* Significant difference between trials $(P<0.05)$.

\section{Skeletal muscle performance}

With PLA, peak torque (Fig. 2(a)) decreased at $6 \mathrm{~h}$ post exercise and remained below baseline until day 4 ( -39 to $-12 \%$, $P<0.05)$, reaching its lowest value at $1 \mathrm{~d}$ of recovery. With PRO, peak torque remained below baseline until day $2(-26 \cdot 5$ to $-20 \%, P<0.005)$ and recovered thereafter. Supplementation with PLA resulted in greater decline of isometric peak torque during the first $5 \mathrm{~d}$ of recovery compared with PRO (day 1: $P=0.02$, ES: $-0.91 ; 95 \% \mathrm{CI}-1 \cdot 79,-0.03$; day 2: $P=0.001$, ES: $-1 \cdot 18$; $95 \%$ CI $-2 \cdot 09,-0 \cdot 27$; day 3: $P=0 \cdot 006$, ES: $-0 \cdot 69$; $95 \% \mathrm{CI}$ $-1,55,0 \cdot 17$; day 4: $P=0 \cdot 003$, ES: $-0 \cdot 67 ; 95 \%$ CI $-1 \cdot 52,0 \cdot 19$; day 5 : $P=0.001$, ES: $-0 \cdot 74 ; 95 \%$ CI $-1 \cdot 61,0 \cdot 12$ ). The online Supplementary Fig. S1 demonstrates percent changes between baseline and two dimensional in muscle strength of all participants. DOMS (Fig. 2(b)) in both trials increased at $6 \mathrm{~h}$ post exercise until day 7 (6h: 4.1-fold in PLA $v$. 3.8-fold in PRO, $P=0.000$; day 1: 6.8-fold in PLA $v$. 5.6-fold in PRO, $P=0.000$; day 2:9.3-fold in PLA $v$. 8.1-fold in PRO, $P=0 \cdot 000$; day 3: 8-fold in PLA $v$. 6.9-fold in PRO, $P=0.000$; day 4: 6.2-fold in PLA $v$. 5.2fold in PRO, $P=0.000$; day 5: 4.5-fold in PLA $v$. 3.8-fold in PRO, $P=0.000$; day 6: 2.7-fold in PLA $v$. 2.2-fold in PRO, $P=0 \cdot 000$; day 7: 1.4-fold in PLA $v$. 1.1-fold in PRO, $P=0.002$ ) and 
(a)

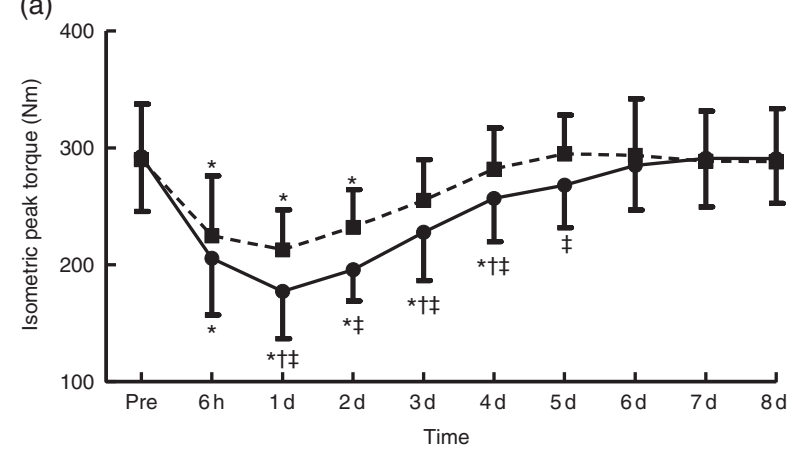

(b)

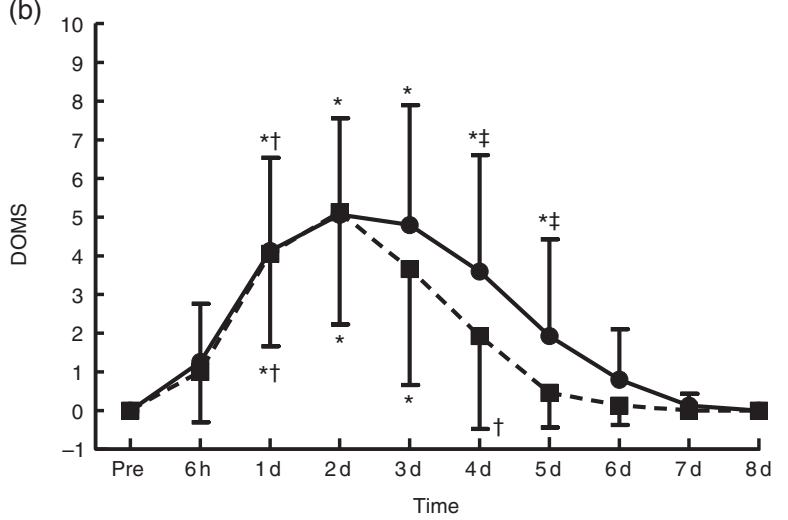

Fig. 2. Changes of muscle performance in response to protein and placebo administration. (a) Isometric peak torque and (b) delayed onset of muscle soreness (DOMS) at baseline (Pre) and throughout recovery in the two trials. Values are means and standard deviations. - - Placebo; - - $_{-}$, protein. * Significantly different from baseline $(P<0.05)$. $\dagger$ Significantly different from the previous time point $(P<0.05)$. $¥$ Significant difference between placebo and protein $(P<0.05)$.

recovered on day 8. The rise in DOMS was of a lower magnitude in PRO compared with PLA on day 1 through day 5 of recovery (day 1: $P=0 \cdot 000$, ES: $1.54 ; 95 \%$ CI 0.58, 2.49; day 2: $P=0 \cdot 000$, ES: $1 \cdot 79 ; 95 \%$ CI $0 \cdot 80,2 \cdot 77$; day 3: $P=0 \cdot 000$, ES: $1 \cdot 17$; $95 \%$ CI $0 \cdot 26,2 \cdot 07$; day $4: P=0 \cdot 002$, ES: $1 \cdot 13$; $95 \% \mathrm{CI}$ $0 \cdot 23,2 \cdot 03$; day 5: $P=0 \cdot 046$, ES: $0 \cdot 62 ; 95 \%$ CI $-0 \cdot 23,1 \cdot 48)$.

\section{Muscle damage and inflammatory responses}

CK (Fig. 3(a)) increased throughout recovery in both trials $(P=0 \cdot 000-0 \cdot 001)$. PRO exhibited a rise of lower magnitude than PLA at $1 \mathrm{~d}(P=0.001$; ES $0.25 ; 95 \% \mathrm{CI}-0.59,1.08)$ and $2 \mathrm{~d}$ $(P=0 \cdot 001$; ES 0.2; $95 \%$ CI $-0 \cdot 64,1 \cdot 04)$. PC (Fig. 3(b)) remained above baseline throughout recovery in PLA, demonstrating a peak on day $2(3-24 \%, P=0 \cdot 000-0 \cdot 002)$. PC in PRO remained elevated until day $2(7-18 \%, P=0 \cdot 000)$, demonstrating a peak on day 2 and recovered thereafter. PC rise was greater in PLA than that in PRO at $1 \mathrm{~d}(P=0.002), 2 \mathrm{~d}(P=0.034 ; \mathrm{ES}: 0.62 ; 95 \%$ $\mathrm{CI}-0 \cdot 2,1 \cdot 44)$ and $8 \mathrm{~d}(P=0 \cdot 037$; ES: $0 \cdot 36 ; 95 \% \mathrm{CI}-0 \cdot 45,1 \cdot 16)$. In both trials, leucocyte counts (Fig. 3(c)) increased $(P<0 \cdot 05)$ $6 \mathrm{~h}$ post exercise, and were maintained above baseline values at $1 \mathrm{~d}$ of recovery and were normalised thereafter. However, there were no significant differences at any time point between PLA and PRO.
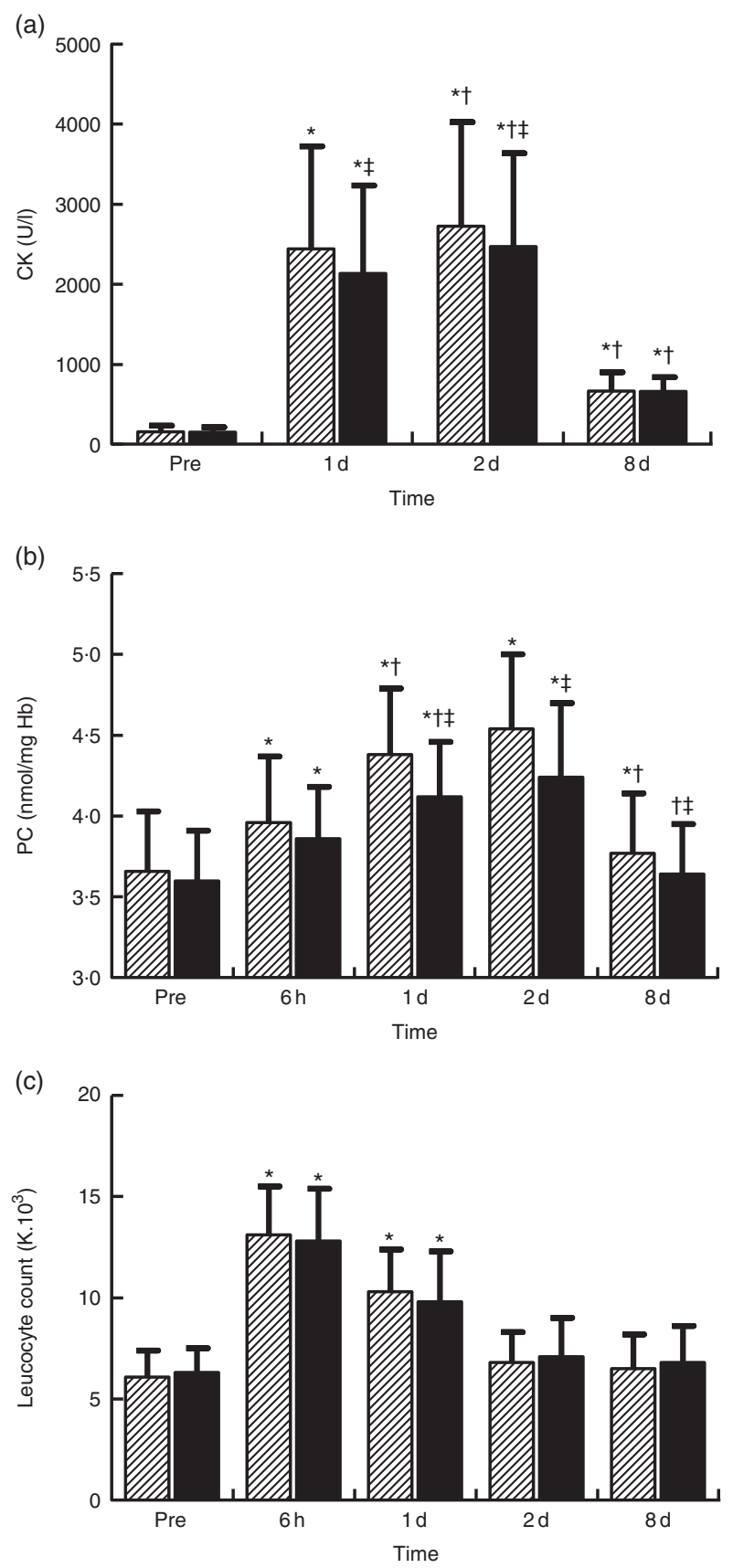

Fig. 3. Changes of muscle damage and inflammatory markers in response to protein and placebo administration. Changes in (a) creatine kinase activity (CK), (b) protein carbonyls (PC) and (c) leucocyte count during the two trials. Values are means and standard deviations represented by vertical bars. Placebo; protein. * Significantly different from baseline $(P<0.05)$. $\dagger$ Significantly different from the previous time point $(P<0.05)$. $\ddagger$ Significant difference between placebo and protein $(P<0.05)$.

\section{Proteasome activity and protein levels}

Proteasome's CT-L activity declined in PLA on day 2 (30\%, $P=0.009$ ) but not in PRO (Fig. 4(a)). Furthermore, the two trials differed in CT-L proteasome activity at $2 \mathrm{~d}(P=0.09$, ES: $-0.75 ; 95 \%$ CI $-1.61,0.12)$. The online Supplementary Fig. S2 demonstrates individual percentage changes (eleven 
(a)

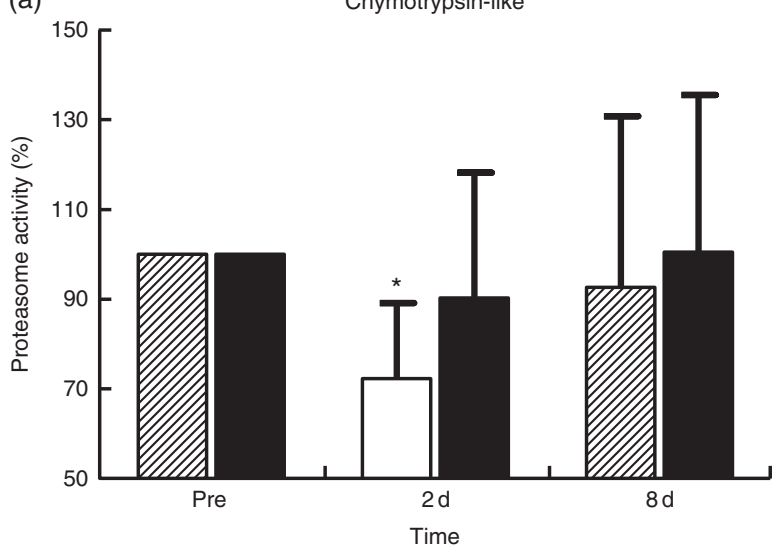

(b)

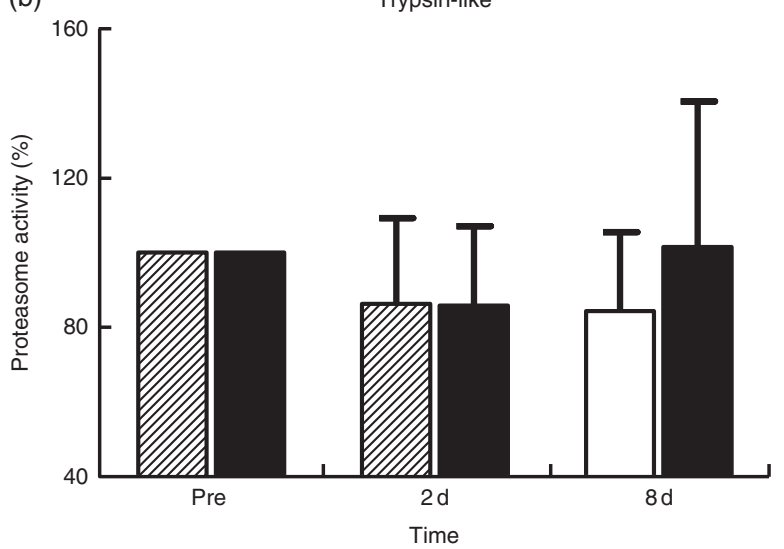

(c)

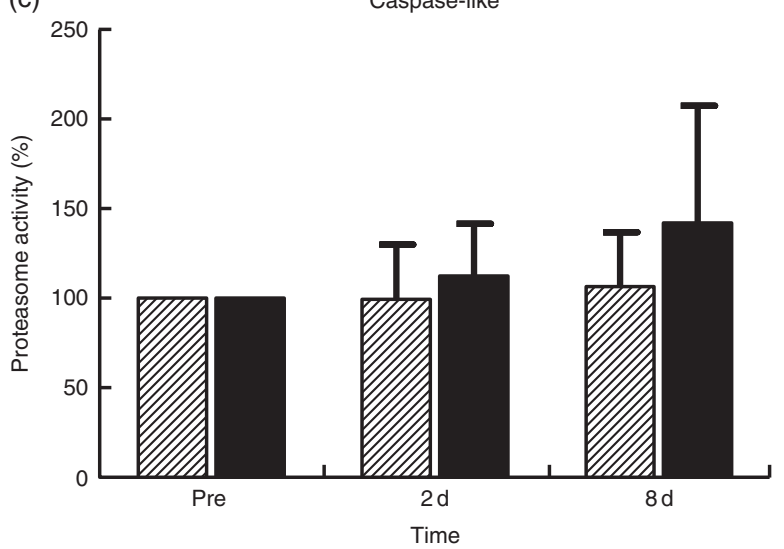

Fig. 4. Changes of proteasome activities in response to protein and placebo administration. Percentage change of (a) chymotrypsin-like activity, (b) trypsinlike activity and (c) caspase-like activity during the two trials. Values are means and standard deviations represented by vertical bars. $\mathbb{Z}$, Placebo; $\square$, protein. * Significantly different from baseline $(P<0.05)$.

participants) in CT-L activity between baseline and $2 \mathrm{~d}$. No changes were observed in T-L (Fig. 4(b)) and C-L (Fig. 4(c)) activities, in both trials. None of the $\beta$-subunit (catalytic proteasomal $\beta$-subunits $\beta 1, \beta 2$ ( $n$ 9) and $\beta 5$ and the corresponding $\beta 1 \mathrm{i}, \beta 2 \mathrm{i}(n$ 8) and $\beta 5 \mathrm{i}$ subunits of immunoproteasome) protein expression levels measured demonstrated any alterations following exercise in both trials (Fig. 5). As a quality control, blood levels of glucose and insulin were measured because increased insulin may lead to Akt phosphorylation and subsequent proteasome inhibition through the forkhead box $O$ $\left(F_{O} X O\right)$ transcription factors ${ }^{(41)}$. Glucose and insulin remained unchanged throughout recovery in both trials (online Supplementary Fig. S3).

\section{Intracellular signalling proteins}

NF- $\kappa$ B phosphorylation (Fig. 6(a), $n$ 8) in PLA increased by approximately $45 \%$ at $2 \mathrm{~d}(P=0.036)$ and by approximately $111 \%$ at $8 \mathrm{~d}(P=0 \cdot 05)$. In PRO, although NF- $\kappa \mathrm{B}$ phosphorylation increased by $18 \%$ at $2 \mathrm{~d}$ and by $130 \%$ at $8 \mathrm{~d}$, no statistical significance was detected for both time points. The online Supplementary Fig. S4 demonstrates individual percentage changes (eight participants) of NF- $\kappa \mathrm{B}$ phosphorylation between baseline and 2 d. Immunoblot analysis for HSP70 ( $n$ 8; Fig. 6(b)) was also performed as it is considered to be a potent activator of proteasome. In PLA, although HSP70 increased at $2 \mathrm{~d}$ by approximately $162 \%$ and at $8 \mathrm{~d}$ by approximately $194 \%$, only the later change was found to be statistically meaningful $(P=0.069)$. HSP70 remained unaffected in PRO throughout recovery ( $2 \mathrm{~d}$ : $18 \%$; $8 \mathrm{~d}$ : $85 \%$ ). The online Supplementary Fig. S5 illustrates individual percentage changes (eight participants) of HSP70 between baseline and $2 \mathrm{~d}$.

\section{Correlations}

Changes in isometric peak torque were not correlated with changes in proteasome activity (CT-L, C-L and T-L) or changes in the protein expression of $\beta$ - $(\beta 5, \beta 2$ and $\beta 1)$ and $\beta$ i-subunits $(\beta 5 \mathrm{i}$, $\beta 2 \mathrm{i}$ and $\beta 1 \mathrm{i})$ at 2 and $8 \mathrm{~d}$. Similarly, no significant correlation was observed between DOMS and either proteasome activity or protein expression of $\beta$ - and $\beta$ i-subunits throughout recovery.

\section{Discussion}

In this study, we investigated the effect of exercise-induced aseptic inflammation and protein ingestion on UPS, muscle damage, inflammatory responses, as well as muscle function. The primary findings of this investigation suggest that milk protein concentrate supplementation may preserve the status of proteasome CT-L activity, as well as accelerate the rate of skeletal muscle strength recovery, under conditions of intense aseptic inflammation.

The extreme model of eccentric exercise applied in this study resulted in severe muscle injury and aseptic inflammation, as indicated by the increased levels of CK, leucocytes, PC and $\mathrm{NF}-\kappa \mathrm{B}$ phosphorylation. Furthermore, in agreement with previous work, we observed a pronounced decline in forcegenerating capacity along with a remarkable elevation in $\operatorname{DOMS}^{(8,30)}$. Although the rise observed in CK exceeded $2000 \mathrm{U} / 1$ during the first $2 \mathrm{~d}$ of recovery, it was of smaller magnitude than that previously observed in response to the same protocol ${ }^{(8)}$. This difference may be attributed to the higher fitness status of participants in this investigation $\left(\mathrm{VO}_{2 \max }\right.$ : 56.4 ( $\mathrm{SD}$ 6.8) $v$. 47.6 (sD 4.5$) \mathrm{ml} / \mathrm{kg}$ per $\mathrm{min}$ ), indicating a superior level of 

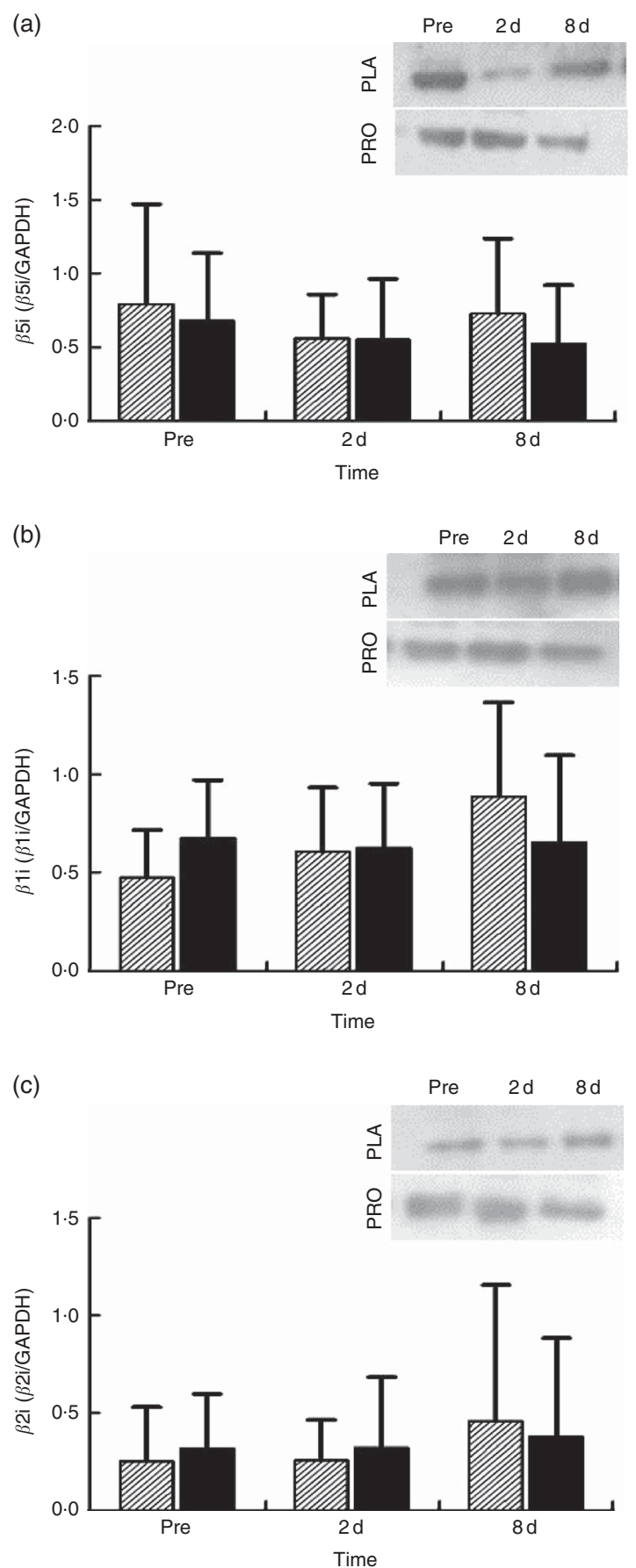
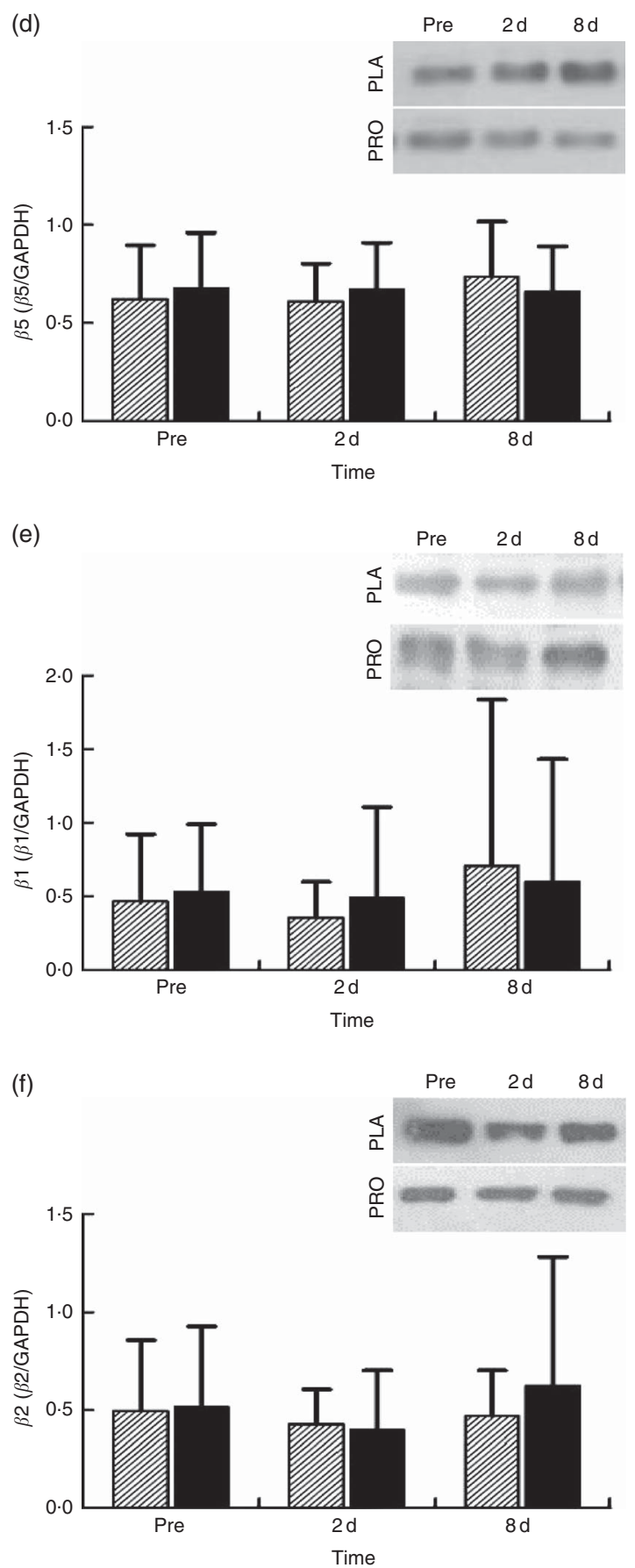

Fig. 5. Changes in the expression of proteasome subunits in response to protein (PRO) and placebo (PLA) administration. Changes in PRO levels of (a) $\beta 5 i$, (b) $\beta 1 \mathrm{i}$, (c) $\beta 2 \mathrm{i}$, (d) $\beta 5$, (e) $\beta 1$ and (f) $\beta 2$ proteasome subunits during the two trials. Values are means and standard deviations represented by vertical bars. $\mathbb{Z}$, PLA; $\square$, PRO.

cardiovascular conditioning, which has been shown to positively affect muscle damage responses ${ }^{(42)}$.

The main proteolytic sites of UPS are hosted in the $\beta 1, \beta 2$ and $\beta 5$ subunits that exhibit C-L, T-L and CT-L activities, respectively ${ }^{(14)}$. Although changes in the mRNA and protein expression of muscle atrophy F-box (MAFbx) and muscle ring finger-1 (MuRF1) have been extensively examined in response to different types and loads of exercise alone ${ }^{(43-46)}$ or in combination with nutritional supplements ${ }^{(47-49)}$, alterations in proteasome activities and expression of the $\beta$-subunits have been investigated to a lesser extent in response to muscle inflammation. To the best of our knowledge, this is the first study examining the responses of $\beta$-subunits, $\beta$ i-subunits (related to the immunoproteasome) and their activities to aseptic inflammation induced by extremely damaging exercise and in combination with protein supplementation. 
(a)

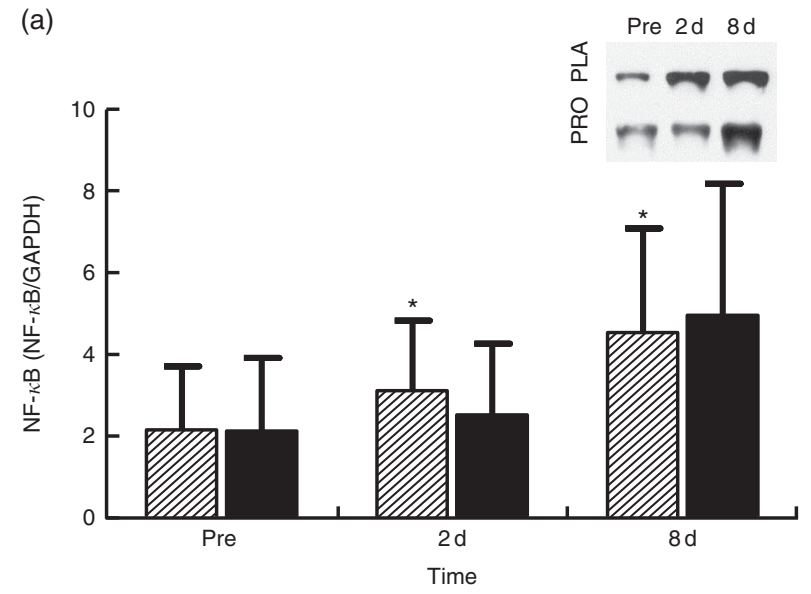

(b)

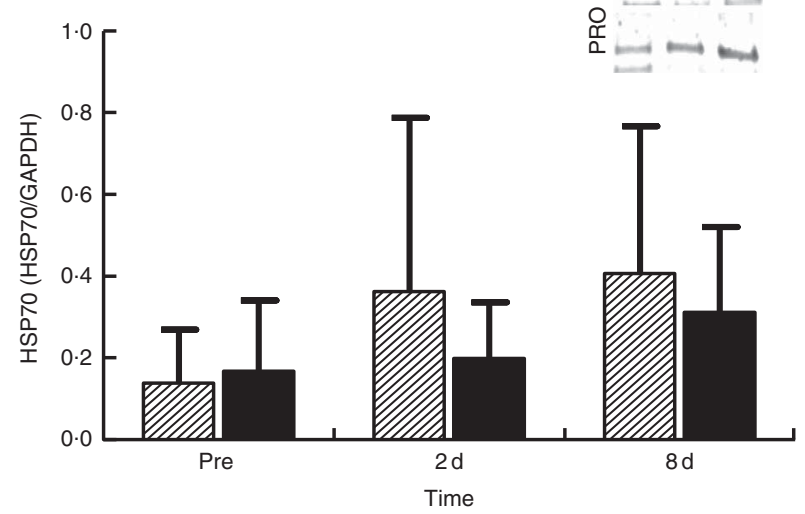

Fig. 6. Changes of molecules regulating proteasome activity in response to protein (PRO) and placebo (PLA) administration. Changes in PRO levels of (a) phosphorylated NF-kB and (b) HSP70 during the two trials. Values are means and standard deviations represented by vertical bars. PLA; $\square$, PRO. Representative immunoblots are shown in panels. * Significantly different from baseline $(P<0.05)$.

Although the UPS proteolytic pathway is upregulated under inflammatory conditions ${ }^{(50,51)}$, it seems that it contributes to the remodelling of skeletal muscle following muscle injury induced by exercise ${ }^{(18)}$. In previous studies, both mRNA and protein levels of ubiquitin ligases (MuRF1 and $M A F b x /$ Atrogin-1) and the $20 \mathrm{~S}$ proteasome have been repeatedly shown to be upregulated following eccentric exercise for as long as $24-48 \mathrm{~h}^{(43,45,52)}$. Moreover, increased CT-L activity has been observed at $14 \mathrm{~d}$ following downhill running ${ }^{(53)}$, further supporting the fundamental role of UPS in skeletal muscle remodelling ${ }^{(18,19)}$. In contrast, we observed a $30 \%$ decrease in CT-L activity at $2 \mathrm{~d}$ post exercise that was not accompanied by any change in protein levels of $20 \mathrm{~S}$ proteasome and immunoproteasome $\beta$-subunits and $\beta$ i-subunits, respectively. It is characteristic that all participants demonstrated a decline of CT-L activity of proteasome at $2 \mathrm{~d}$, suggesting that there was limited inter-individual variability on this outcome. Interestingly, our data corroborate previous findings, showing decreased CT-L activity (by $21 \%$ ) in response to extreme exercise such as a $200-\mathrm{km}$ run $^{(54)}$. The authors assumed that an inhibitory mechanism results in the decline of proteasomal activity in response to increased load of oxidative stress $^{(54)}$. This assumption may also be valid in our case, as the 300 eccentric contractions protocol performed in our present study resulted in pronounced oxidative stress (40-95\%) and inflammatory responses that persisted throughout the recovery phase, especially in PLA, a response also reported previously ${ }^{(8)}$. Likewise, a 200-km run, another form of excessive exercise resulting in EIMD, induced a marked increase in metallothionein $1 \mathrm{~F}$, metalothionein $1 \mathrm{H}$ and NADPH oxidase by approximately 519,666 and $162 \%$, respectively ${ }^{(54)}$. Therefore, reduced proteasomal activity has been observed only in response to cases of extreme exercise models (e.g., ultra-marathons, high-volume eccentric exercise) that predispose skeletal muscle to excessive ROS production and redox status disturbances. In agreement with this theory, an excessive amount of protein carbonylation in SH-SY5Y cells has been shown to cause a substantial decrease in proteasome S6 ATPase activity and 26S proteasome-mediated degradation $^{(55)}$

On the other hand, protein supplementation prevented the decline of proteasome activity. Preservation of UPS activity, and as such clearance of oxidised proteins, might have also contributed to the accelerated recovery of the skeletal muscle following damaging exercise. Interestingly, individual changes of CT-L proteasomal activity at $2 \mathrm{~d}$ are very similar, with eight out of eleven subjects exhibiting either maintained or enhanced CT-L proteasomal activity and only three participants exhibiting reduced CT-L proteasomal activity in PRO. To explain this response, we measured changes in HSP70 expression and NF- $\kappa$ B phosphorylation. The molecular chaperone HSP70 protein is considered to directly activate the $26 \mathrm{~S}$ proteasome activity, thereby preventing the accumulation of unfolding proteins and aggregates $^{(56,57)}$. HSP70 increased markedly at 2 and $8 \mathrm{~d}$ post exercise, but this rise was more pronounced in PLA compared with PRO. Indeed, it has been reported that HSP70 exhibits an intensity-dependent response to exercise ${ }^{(58)}$. Furthermore, its expression has been shown to increase under conditions of elevated oxidative stress (as in this case) to promote degradation of oxidised proteins through the $20 \mathrm{~S}$ proteasome following its dissociation with $26 \mathrm{~S}^{(56,59)}$. Interestingly, HSP70 has been shown to mediate the dissociation and re-association of the $26 \mathrm{~S}$ proteasome in response to oxidative damage induced by an acute rise of ROS ${ }^{(59)}$. Therefore, the lower HSP70 response in PRO compared with that observed in PLA may have contributed to the lack of an adverse exercise effect on proteasome activity in PRO. Although the two trials demonstrated HSP70 changes of considerable difference in magnitude, no statistically meaningful differences were detected. However, when individual responses are observed, it is obvious that the vast majority of participants (six out of eight exhibited a reduced response in $\mathrm{PRO}$, one had a similar response in the two trials and one had a more pronounced response in $\mathrm{PRO}$ ) demonstrated a reduced HSP70 response in PRO compared with PLA.

The NF- $\kappa$ B pathway is one of the main redox-sensitive signalling pathways that regulates inflammatory and oxidative stress responses in human skeletal muscle ${ }^{(1,5,60)}$. It may be activated in response to elevated pro-inflammatory mediators and ROS, but it also controls the expression of genes including 
cytokines such as TNF- $\alpha$, IL- 6 and IL- $1 \beta$, suggesting a vicious cycle between $\mathrm{NF}-\kappa \mathrm{B}$ activation, inflammatory and oxidative stress responses ${ }^{(15,61)}$. The increased phosphorylation of NF- $\kappa \mathrm{B}$ observed following eccentric exercise was mitigated by PRO (although it was not found to be statistically meaningful, NF- $\kappa \mathrm{B}$ phosphorylation was lower in PRO compared with PLA by approximately $26 \%$ at $2 \mathrm{~d}$ and approximately $23 \%$ at $8 \mathrm{~d}$ ). When individual responses are taken into account at $2 \mathrm{~d}$, it appears that $50 \%$ of participants showed an attenuated NF- $\kappa$ B response in PRO and $50 \%$ did not. Similar perturbations of NF- $\kappa \mathrm{B}$ signalling following aseptic muscle injury have been observed with ingestion of thiol-based and other antioxidants ${ }^{(8,62)}$

Because insulin levels may also interfere with UPS through the IGF1-Akt-FOXO signalling pathway ${ }^{(11,48)}$, we measured glucose and insulin levels during recovery. Both glucose and insulin remained unaltered throughout recovery, suggesting that they had no impact on proteasome activity. This also indicates that the reduction observed in CT-L activity at $2 \mathrm{~d}$ was clearly induced by the exercise stimulus per se.

In our present study, protein supplementation resulted in the attenuation of markers of muscle damage as evidenced by CK and DOMS values during the post-exercise recovery. Specifically, the elevation of both plasma CK and reported DOMS was greater in the PLA group compared with the PRO group. This effect might be explained by the high BCAA content of milk protein ${ }^{(63)}$, which has been shown to attenuate DOMS following damaging exercise when consumed in adequate amounts ${ }^{(24,64)}$. However, a number of studies reported no effect in response to BCAA supplementation ${ }^{(65,66)}$. This discrepancy among studies may be attributed to differences in the length of the supplementation period, as well as the amount of BCAA administered. For instance, in the study by Nosaka et al. ${ }^{(65)}$, it was clearly shown that in contrast to acute supplementation (before and after exercise) long-term supplementation (before and after exercise and at eight more occasions) with amino acids during exercise recovery results in lower plasma CK and muscle soreness.

Soreness develops because of sensitisation of nociceptors at the level of the perimysium and epimysium by various inflammatory stimuli ${ }^{(64,67)}$. In accordance with the above, in our present study, we observed an increase in $\mathrm{CK}, \mathrm{PC}, \mathrm{NF}-\kappa \mathrm{B}$ in PLA, whereas PRO resulted in attenuated inflammatory responses. Therefore, it is likely that protein supplementation reduces DOMS via the attenuation of specific inflammatory markers. An alternative mechanism explaining this protein effect on DOMS may be related to feeding per se, but a mechanism relating these two is lacking ${ }^{(24,25)}$.

In line with others, protein suppressed the exercise-induced decline in force-generating capacity and resulted in a faster strength recovery compared with PLA ${ }^{(21,22)}$. Although the molecular mechanisms are still obscure, recent evidence suggests that amino acids may promote muscle repair and remodelling by attenuating the excessive inflammatory responses following injury $^{(68-70)}$. In fact, administration of a leucine-enriched protein supplement ( $70 \mathrm{~g}$ protein $/ 15 \mathrm{~g}$ leucine) following high-intensity endurance exercise activated a pro-inflammatory transcriptome at $30 \mathrm{~min}$ and promoted an anti-inflammatory and pro-myogenic transcriptome at $4 \mathrm{~h}$, characterised by decreased leucocyte migration $^{(69)}$. The transition from a pro- to an anti-inflammatory phenotype, mediated by the progressive shift of M1 macrophages to $M 2$, is pivotal for muscle regeneration and growth ${ }^{(60)}$. In this study, PRO attenuated exercise-induced inflammatory response, as evidenced by the reduced PC and CK, as well as the unaltered phosphorylation levels of NF- $\kappa \mathrm{B}$ at 2 and $8 \mathrm{~d}$. Thus, PRO may have resulted in a faster transition to an anti-inflammatory phenotype and consequently an accelerated recovery of muscle function. $\mathrm{NF}-\kappa \mathrm{B}$ activation may inhibit myogenesis and increase the expression of many pro-inflammatory cytokines (e.g. TNF- $\alpha$, IL- 6 and $\mathrm{IL}-1 \beta$ ) that are able to amplify the inflammatory response ${ }^{(60)}$. A recent animal study reported decreased IL-6 expression and enhanced muscle performance after damaging exercise following supplementation with leucine-enriched essential amino acids ${ }^{(68)}$. Moreover, during phagocytosis, infiltrating neutrophils generate ROS through the NADPH oxidase, a phenomenon known as oxidative burst, which induces secondary damage in skeletal muscle $^{(71)}$. The lower PC levels observed in PRO may suggest, among others, reduced ROS generation that indicates reduced oxidative burst and as such smaller secondary muscle damage. This mechanism may also explain the attenuated reduction of forcegenerating capacity in PRO during recovery, as previously shown with thiol-based antioxidant supplementation in humans ${ }^{(8,72)}$.

Proteasome activity though was not correlated with peak isometric torque and DOMS, suggesting that neither the former nor the latter is related directly to UPS. In contrast to these findings, the study of Pereira et al. ${ }^{(70)}$ provided evidence that leucine supplementation in rats, after induction of muscle damage through cryolesion, improved muscle function via suppression of protein ubiquitination and decreased activation of FOX3a at days 3 and 10 of recovery. The discrepancy with that study may be partly explained by the fact that Pereira et $a{ }^{(70)}$ measured protein ubiquitination and expression of FOXO family transcription factors that lead to activation of E3 ligases, whereas we evaluated the direct proteasome activity and expression of specific catalytic subunits. Moreover, transcription factors other than FOXO1 and FOXO3a are probably responsible for the activation of E3 ubiquitin ligases in humans (e.g. MuRF1 and $M A F b x /$ Atrogin-1) as compared with animals ${ }^{(73)}$.

\section{Conclusions}

This is the first investigation showing that under severe aseptic inflammation proteasomic activity may be severely impaired. Protein supplementation may not only prevent the attenuation of proteasome activity possibly via the expression of HSP70, reduced oxidative stress and altered $\mathrm{NF}-\kappa \mathrm{B}$ phosphorylation but also results in reduced muscle discomfort and an acceleration of skeletal muscle strength recovery. These results suggest that PRO may provide a viable nutritional intervention to enhance muscle remodelling and maintain muscle function under conditions of increased inflammation induced by exercise.

\section{Acknowledgements}

The authors acknowledge the subjects for their participation and commitment to the study.

The authors received departmental funding for this study.

D. D., N. C., A. C., G. T., L. G. K., A. Z. J. and I. G. F. contributed to the research design. D. D., N. C., A. C., G. T., A. S., 
A. A., M. P., A. Z. J. and I. G. F. contributed to study implementation. D. D., N. C., A. C., A. S., A. A., M. L., M. P., C. K. D., L. G. K. and I. G. F. performed the sample analysis and data interpretation. D. D., N. C., L. G. K. and I. G. F. wrote the first version of the manuscript. All authors contributed to the paper, reviewed it and approved the final version of the manuscript.

The authors declare that there are no conflicts of interest.

\section{Supplementary material}

For supplementary material/s referred to in this article, please visit https://doi.org/10.1017/S0007114517001829

\section{References}

1. Peake J, Nosaka K \& Suzuki K (2005) Characterization of inflammatory responses to eccentric exercise in humans. Exerc Immunol Rev 11, 64-85.

2. Fehrenbach E \& Schneider ME (2006) Trauma-induced systemic inflammatory response versus exercise-induced immunomodulatory effects. Sports Med 36, 373-384.

3. Nikolaidis MG, Jamurtas AZ, Paschalis V, et al. (2008) The effect of muscle-damaging exercise on blood and skeletal muscle oxidative stress: magnitude and time-course considerations. Sports Med 38, 579-606.

4. Powers SK, Ji LL, Kavazis AN, et al. (2011) Reactive oxygen species: impact on skeletal muscle. Compr Physiol 1, 941-969.

5. Ji LL (2007) Antioxidant signaling in skeletal muscle: a brief review. Exp Gerontol 42, 582-593.

6. Aoi W, Naito Y, Takanami Y, et al. (2004) Oxidative stress and delayed-onset muscle damage after exercise. Free Rad Biol Med 37, 480-487.

7. Palacio JR, Markert UR \& Martinez P (2011) Anti-inflammatory properties of $\mathrm{N}$-acetylcysteine on lipopolysaccharide-activated macrophages. Inflamma Res 60, 695-704.

8. Michailidis Y, Karagounis LG, Terzis G, et al. (2013) Thiol-based antioxidant supplementation alters human skeletal muscle signaling and attenuates its inflammatory response and recovery after intense eccentric exercise. Am J Clin Nutr 98, 233-245.

9. Powers SK, Morton AB, Ahn B, et al. (2016) Redox control of skeletal muscle atrophy. Free Radic Biol Med 98, 208-217.

10. Olaso-Gonzalez G, Ferrando B, Derbre F, et al. (2014) Redox regulation of E3 ubiquitin ligases and their role in skeletal muscle atrophy. Free Radic Biol Med 75, Suppl. 1, S43-S44.

11. Schiaffino S, Dyar KA, Ciciliot S, et al. (2013) Mechanisms regulating skeletal muscle growth and atrophy. FEBS $J \mathbf{2 8 0}$, 4294-4314.

12. Sandri M (2013) Protein breakdown in muscle wasting: role of autophagy-lysosome and ubiquitin-proteasome. Int J Biochem Cell Biol 45, 2121-2129.

13. Jung $\mathrm{T} \&$ Grune $\mathrm{T}$ (2008) The proteasome and its role in the degradation of oxidized proteins. IUBMB Life 60, 743-752.

14. Chondrogianni N, Petropoulos I, Grimm S, et al. (2014) Protein damage, repair and proteolysis. Mol Aspects Med 35, 1-71.

15. Li H, Malhotra S \& Kumar A (2008) Nuclear factor-kappa B signaling in skeletal muscle atrophy. J Mol Med (Berl) 86, 1113-1126.

16. Puig-Vilanova E, Rodriguez DA, Lloreta J, et al. (2015) Oxidative stress, redox signaling pathways, and autophagy in cachectic muscles of male patients with advanced COPD and lung cancer. Free Radic Biol Med 79, 91-108.

17. Bell RA, Al-Khalaf M \& Megeney LA (2016) The beneficial role of proteolysis in skeletal muscle growth and stress adaptation. Skelet Muscle 6, 16.
18. Taillandier D, Combaret L, Pouch MN, et al. (2004) The role of ubiquitin-proteasome-dependent proteolysis in the remodelling of skeletal muscle. Proc Nutr Soc 63, 357-361.

19. Murton AJ, Constantin D \& Greenhaff PL (2008) The involvement of the ubiquitin proteasome system in human skeletal muscle remodelling and atrophy. Biochimi Biophys Acta 1782, 730-743.

20. Nicastro H, da Luz CR, Chaves DF, et al. (2012) Does branched-chain amino acids supplementation modulate skeletal muscle remodeling through inflammation modulation? Possible mechanisms of action. J Nutr Metab 2012, 136937.

21. Cooke MB, Rybalka E, Stathis CG, et al. (2010) Whey protein isolate attenuates strength decline after eccentrically-induced muscle damage in healthy individuals. J Int Soc Sports Nutr 7, 30.

22. Buckley JD, Thomson RL, Coates AM, et al. (2010) Supplementation with a whey protein hydrolysate enhances recovery of muscle force-generating capacity following eccentric exercise. J Sci Med Sport 3, 178-181.

23. Farup J, Rahbek SK, Knudsen IS, et al. (2014) Whey protein supplementation accelerates satellite cell proliferation during recovery from eccentric exercise. Amino Acids $\mathbf{4 6}$, $2503-2516$

24. Howatson G, Hoad M, Goodall S, et al. (2012) Exerciseinduced muscle damage is reduced in resistance-trained males by branched chain amino acids: a randomized, double-blind, placebo controlled study. J Int Soc Sports Nutr 9, 20.

25. Jackman SR, Witard OC, Jeukendrup AE, et al. (2010) Branched-chain amino acid ingestion can ameliorate soreness from eccentric exercise. Med Sci Sports Exerc 42, 962-970.

26. Cruzat VF, Krause M \& Newsholme P (2014) Amino acid supplementation and impact on immune function in the context of exercise. J Int Soc Sports Nutr 11, 61.

27. Elango R, Humayun MA, Ball RO, et al. (2010) Evidence that protein requirements have been significantly underestimated. Curr Opin Clin Nutr Metab Care 13, 52-57.

28. Humayun MA, Elango R, Ball RO, et al. (2007) Reevaluation of the protein requirement in young men with the indicator amino acid oxidation technique. American J Clin Nutr 86, 995-1002.

29. Chatzinikolaou A, Christoforidis C, Avloniti A, et al. (2014) A microcycle of inflammation following a team handball game. J Strength Cond Res 28, 1981-1994.

30. Raastad T, Owe SG, Paulsen G, et al. (2010) Changes in calpain activity, muscle structure, and function after eccentric exercise. Med Sci Sports Exerc 42, 86-95.

31. Areta JL, Burke LM, Ross ML, et al. (2013) Timing and distribution of protein ingestion during prolonged recovery from resistance exercise alters myofibrillar protein synthesis. J Physiol 591, 2319-2331.

32. Moore DR, Areta J, Coffey VG, et al. (2012) Daytime pattern of post-exercise protein intake affects whole-body protein turnover in resistance-trained males. Nutr Metab 9, 91.

33. Naclerio F, Larumbe-Zabala E, Ashrafi N, et al. (2017) Effects of protein-carbohydrate supplementation on immunity and resistance training outcomes: a double-blind, randomized, controlled clinical trial. Eur J Appl Physiol 117, 267-277.

34. Volek JS, Volk BM, Gomez AL, et al. (2013) Whey protein supplementation during resistance training augments lean body mass. J Am Coll Nutr 32, 122-135.

35. Theodorou AA, Nikolaidis MG, Paschalis V, et al. (2010) Comparison between glucose-6-phosphate dehydrogenasedeficient and normal individuals after eccentric exercise. Med Sci Sports Exerc 42, 1113-1121.

36. Barbas I, Fatouros IG, Douroudos II, et al. (2011) Physiological and performance adaptations of elite Greco-Roman wrestlers during a one-day tournament. Eur J Appl Physiol 111, 1421-1436. 
37. Kraemer WJ, Solomon-Hill G, Volk BM, et al. (2013) The effects of soy and whey protein supplementation on acute hormonal reponses to resistance exercise in men. $J$ Am Coll Nutr 32, 66-74.

38. Terzis G, Stratakos G, Manta P, et al. (2008) Throwing performance after resistance training and detraining. $J$ Strength Cond Res 22, 1198-1204.

39. Chondrogianni N, Stratford FL, Trougakos IP, et al. (2003) Central role of the proteasome in senescence and survival of human fibroblasts: induction of a senescence-like phenotype upon its inhibition and resistance to stress upon its activation. J Biol Chem 278, 28026-28037.

40. Myeku N, Metcalfe MJ, Huang Q, et al. (2011) Assessment of proteasome impairment and accumulation/aggregation of ubiquitinated proteins in neuronal cultures. Methods Mol Biol 793, 273-296.

41. Sala D \& Zorzano A (2015) Differential control of muscle mass in type 1 and type 2 diabetes mellitus. Cell Mol Life Sci $\mathbf{7 2}$, 3803-3817.

42. Morton JP, Kayani AC, McArdle A, et al. (2009) The exerciseinduced stress response of skeletal muscle, with specific emphasis on humans. Sports Med 39, 643-662.

43. Rom O \& Reznick AZ (2016) The role of E3 ubiquitin-ligases MuRF-1 and MAFbx in loss of skeletal muscle mass. Free Radic Biol Med 98, 218-230.

44. Stefanetti RJ, Lamon S, Wallace M, et al. (2015) Regulation of ubiquitin proteasome pathway molecular markers in response to endurance and resistance exercise and training. Pflugers Arch 467, 1523-1537.

45. Reid MB (2005) Response of the ubiquitin-proteasome pathway to changes in muscle activity. Am J Physiol Regul Integr Comp Physiol 288, R1423-R1431.

46. Nedergaard A, Vissing K, Overgaard K, et al. (2007) Expression patterns of atrogenic and ubiquitin proteasome component genes with exercise: effect of different loading patterns and repeated exercise bouts. J Appl Physiol (1985) 103, 1513-1522.

47. Borgenvik M, Apro W \& Blomstrand E (2012) Intake of branched-chain amino acids influences the levels of MAFbx mRNA and MuRF-1 total protein in resting and exercising human muscle. Am J Physiol Endocrinol Metab 302, E510-E521.

48. Greenhaff PL, Karagounis LG, Peirce N, et al. (2008) Disassociation between the effects of amino acids and insulin on signaling, ubiquitin ligases, and protein turnover in human muscle. Am J Physiol Endocrinol Metab 295, E595-E604.

49. Rahbek SK, Farup J, de Paoli F, et al. (2015) No differential effects of divergent isocaloric supplements on signaling for muscle protein turnover during recovery from muscledamaging eccentric exercise. Amino Acids 47, 767-778.

50. Bowen TS, Schuler G \& Adams V (2015) Skeletal muscle wasting in cachexia and sarcopenia: molecular pathophysiology and impact of exercise training. J Cachexia, Sarcopenia Muscle 6, 197-207.

51. Onesti JK \& Guttridge DC (2014) Inflammation based regulation of cancer cachexia. Biomed Res Int 2014, 168407.

52. Kostek MC, Chen YW, Cuthbertson DJ, et al. (2007) Gene expression responses over $24 \mathrm{~h}$ to lengthening and shortening contractions in human muscle: major changes in CSRP3, MUSTN1, SIX1, and FBXO32. Physiol Genomics 31, 42-52.

53. Feasson L, Stockholm D, Freyssenet D, et al. (2002) Molecular adaptations of neuromuscular disease-associated proteins in response to eccentric exercise in human skeletal muscle. J Physiol 543, 297-306.

54. Kim HJ, Jamart C, Deldicque L, et al. (2011) Endoplasmic reticulum stress markers and ubiquitin-proteasome pathway activity in response to a 200-km run. Med Sci Sports Exerc 43, 18-25.
55. Ishii T, Sakurai T, Usami H, et al. (2005) Oxidative modification of proteasome: identification of an oxidation-sensitive subunit in $26 \mathrm{~S}$ proteasome. Biochemistry 44, 13893-13901.

56. Reeg S, Jung T, Castro JP, et al. (2016) The molecular chaperone Hsp70 promotes the proteolytic removal of oxidatively damaged proteins by the proteasome. Free Radic Biol Med 99, 153-166.

57. Um JW, Im E, Lee HJ, et al. (2010) Parkin directly modulates 26S proteasome activity. J Neurosci 30, 11805-11814.

58. Liu Y, Lormes W, Baur C, et al. (2000) Human skeletal muscle HSP70 response to physical training depends on exercise intensity. Int J Sports Med 21, 351-355.

59. Grune T, Catalgol B, Licht A, et al. (2011) HSP70 mediates dissociation and reassociation of the $26 \mathrm{~S}$ proteasome during adaptation to oxidative stress. Free Radic Biol Med 51, 1355-1364.

60. Tidball JG \& Villalta SA (2010) Regulatory interactions between muscle and the immune system during muscle regeneration. Am J Physiol Regul Integr Comp Physiol 298, R1173-R1187.

61. Draganidis D, Karagounis LG, Athanailidis I, et al. (2016) Inflammaging and skeletal muscle: can protein intake make a difference? J Nutr 146, 1940-1952.

62. Gomez-Cabrera MC, Martinez A, Santangelo G, et al. (2006) Oxidative stress in marathon runners: interest of antioxidant supplementation. Br J Nutr 96, Suppl. 1, S31-S33.

63. Bendtsen LQ, Lorenzen JK, Bendsen NT, et al. (2013) Effect of dairy proteins on appetite, energy expenditure, body weight, and composition: a review of the evidence from controlled clinical trials. Adv Nutr 4, 418-438.

64. Shimomura Y, Inaguma A, Watanabe S, et al. (2010) Branched-chain amino acid supplementation before squat exercise and delayed-onset muscle soreness. Int J Sport Nutr Exerc Metab 20, 236-244.

65. Nosaka K, Sacco P \& Mawatari K (2006) Effects of amino acid supplementation on muscle soreness and damage. Int J Sport Nutr Exerc Metab 16, 620-635.

66. White JP, Wilson JM, Austin KG, et al. (2008) Effect of carbohydrate-protein supplement timing on acute exerciseinduced muscle damage. J Int Soc Sports Nutr 5, 5.

67. Proske U \& Morgan DL (2001) Muscle damage from eccentric exercise: mechanism, mechanical signs, adaptation and clinical applications. J Physiol 537, 333-345.

68. Kato H, Miura K, Nakano S, et al. (2016) Leucine-enriched essential amino acids attenuate inflammation in rat muscle and enhance muscle repair after eccentric contraction. Amino Acids 48, 2145-2155.

69. Rowlands DS, Nelson AR, Raymond F, et al. (2016) Proteinleucine ingestion activates a regenerative inflammo-myogenic transcriptome in skeletal muscle following intense endurance exercise. Physiol Genomics 48, 21-32.

70. Pereira MG, Baptista IL, Carlassara EO, et al. (2014) Leucine supplementation improves skeletal muscle regeneration after cryolesion in rats. PLOS ONE 9, e85283.

71. Kyriakides C, Austen W Jr., Wang Y, et al. (1999) Skeletal muscle reperfusion injury is mediated by neutrophils and the complement membrane attack complex. Am J Physiol 277, C1263-C1268.

72. Cobley JN, McGlory C, Morton JP, et al. (2011) N-Acetylcysteine's attenuation of fatigue after repeated bouts of intermittent exercise: practical implications for tournament situations. Int J Sport Nutr Exerc Metab 21, 451-461.

73. Stefanetti RJ, Lamon S, Rahbek SK, et al. (2014) Influence of divergent exercise contraction mode and whey protein supplementation on atrogin-1, MuRF1, and FOXO1/3A in human skeletal muscle. J Appl Physiol (1985) 116, 1491-1502. 